American Journal of Environmental Sciences 5 (5): 613-617, 2009

ISSN 1553-345X

(C) 2009 Science Publications

\title{
Measurements and Model Calibration of Urban Traffic Noise Pollution
}

\author{
N. Al-Mutairi, F. Al-Rukaibi and P. Koushki \\ Department of Civil Engineering, P.O. Box 5969 Safat, Kuwait 13060
}

\begin{abstract}
Problem statement: The problem of urban traffic noise pollution is universal and in the past few decades it has grown to the point that it has become a major concern for both the public and the policy-makers. Approach: In a comprehensive 18 month research project, traffic-generated noise was monitored at 47 roadway locations in fourteen districts in metropolitan Kuwait in 2004-2005. Simultaneously with noise, traffic flow variables of volume-by mix and traffic speed were also measured. Measurements of noise and traffic flow variables were performed for a period of $20 \mathrm{~min}$ at each location, repeated 3-5 times, during peak and off-peak hours to account for time-fluctuation of these variables. At each district, a sample of freeway, arterial, collector and local residential streets were included in the noise and traffic flow monitoring plan. In addition to the analysis of noise, flow and their interrelationships, two models-regressions and the FHWA's traffic noise model, were employed to predict noise pollutions from traffic. Results: Findings indicated that traffic noise is at or above, the standard outdoor limits in most locations and especially at arterial roadways and freeways. Recommendations concerning measured to improve the problem of urban traffic noise pollution in Kuwait are also made. Conclusion: Findings of this research project had shown that level of trafficgenerated noise pollution in Kuwait urban area is high enough to adversely affect the welfare activities and productivities of its residents. With the rapidly growing rate of infrastructural development and unplanned urban land-use change, it is almost certain, that problem of urban traffic noise pollution will soon assume a critical dimension and will be a cause of increasing concern for both public and responsible policy-makers. The quality of urban life will undoubtedly be adversely affected.
\end{abstract}

Key words: Noise pollution, noise models, noise from traffic, Kuwait

\section{INTRODUCTION}

The affluent State of Kuwait has experienced a very rapid growth rate in the socio-economic and infrastructures over the last three decades. The construction of hundreds of kilometers of urban freeways, arterials and flyovers has complemented the intense development of the socio-economic sectors. With a population of over two and half million and a vehicle fleet of more than one million and both growing rapidly metropolitan Kuwait is experiencing increasing volumes of traffic, greater trip frequency and increasing trip length. Quite naturally, the level of generated noise from traffic is also expected to rise.

As far back as 1995, formal complaints concerning traffic noise were received by the Department of Environment of Kuwait Municipality, from the residents of two districts in metropolitan Kuwait ${ }^{[1]}$. With the growth in urban population, auto ownership and travel, more and more people will be adversely affected by the problem of traffic generated noise pollution in Kuwait.
Traffic noise pollution has become a pervasive aspect of working and living environments in most urban areas of the world, especially those in developing nations ${ }^{[2-5]}$ over the last three to four decades. The escalating problems of air and noise pollutions caused by traffic are receiving top priority attention and resources from governments, the private sector and the public all over the world as they struggle to control these negative environmental concomitants of transport systems $^{[6]}$.

In non-industrialized nations, the problem of urban noise pollution growth follows the same route which other urban areas in technologically advanced countries have followed. However, the problems assumes an even more complex dimension than that of the developed nations. All major cities in developing nations are over populated, a continuous migration from rural to urban areas is in the process, there is a lack of proper city planning and practically no control strategies for reducing the level of noise from various sources. Recent research indicates that in all major urban areas of India, for example, the mean 
noise level is more than twice the prescribed international limits ${ }^{[3]}$.

In preliminary research, traffic flow variables of volume, mix and speed as well as the noise from traffic were measured at nine roadway locations in Kuwait City $^{[7]}$. The measured level of noise $\left(\mathrm{L}_{\mathrm{eq}}\right)$ at roadway edge was in the upper $70 \mathrm{~s} \mathrm{~dB}(\mathrm{~A})$ at the sample local street in the $80 \mathrm{~s} \mathrm{~dB}(\mathrm{~A})$ at the arterial and freeway locations. The standard limit for the outdoor noise level is $75 \mathrm{~dB}(\mathrm{~A})$, which points to the noisiness of urban environment at the vicinity of major roadways in Kuwait.

Noise levels were also measured, for the first time, inside 115 randomly-selected transit buses, operating on 12 sample representative routes in Metropolitan Kuwait $^{[8]}$. Simultaneously with the monitoring of noise levels, the attitudes of 679 riders concerning the annoyance and long-term health impacts of noise were also surveyed. The measured noise levels and the computed traffic noise levels inside transit buses were generally high. The study concluded that the inside of transit buses during the daily commuting hours was generally noisy.

A similar study in Riyadh, Saudi Arabia, was also performed. Based on the results of a comprehensive monitoring of traffic noise, the study concluded that the arterial roadways in Riyadh were noisy and that the level of noise pollution at major roadways in Riyadh exceeded the permissible international standards by a significant margarine ${ }^{[9]}$.

The specific objectives of the study were to: Measure traffic-generated noise levels during peak and off-peak hours, monitor traffic flow variables simultaneously with noise measurements, examine causal relationships between traffic flow variables and noise pollution levels and evaluate the applicability of the FHWA Traffic Noise Model to predict noise levels in Kuwait.

\section{MATERIALS AND METHODS}

In order to develop the database for the project, a structured framework was first established. The framework addressed the type and the size of the data required to accomplish the research objectives as well as to facilitate the processing of the data for the analysis.

Two types of data were collected for the database:

- Traffic noise levels

- Traffic flow variables
A pre-requisite to the start of the monitoring of traffic noise and flow variables was the identification of representative sample roadway sites. The sites were selected (from the city map) such that a representative sample of each of the four roadway classes: freeways, arterials, collectors and local streets, would included in the monitoring sample. In addition, the selection of the sample sites was made to address the variations in the level of physical, land-use development and general population density existing among various districts in metropolitan Kuwait. A total of thirty nine sample roadway sites, located in thirteen districts were selected for monitoring traffic volume, mix, speed, number of traffic lanes, site characteristics and noise pollution levels. In addition, eight roadway sites were also monitored for traffic flow and noise pollution levels for the calibration and comparison of predicted noise by the US FHWA Traffic Noise Model ${ }^{[10]}$ and the $\mathrm{UK}^{[11]}$. The data for these additional eight roadway sites were collected in accordance with the requirements of the models for calibration and validation.

Traffic flow and noise levels were measured simultaneously during the daily peak and off-peak periods, for $20 \mathrm{~min}$ at each selected roadway site. Measurements were repeated three times, spread over different weeks, at each location. The monitoring periods ranged from 7:30-8:30 am, 3:00-4:30 pm and 5:30-8:30 pm (evening). The hand-tally method was employed to count traffic volume and mix. Radar speed measuring device was used to record the speed of traffic.

Traffic noise was measured with Bruel and Kjaer sound level meters (Precision Integrating Sound Level Meter Type 2236), along with a type 4166 outdoor microphone unit. The microphone was located on the sidewalk at the edge of the roadway traffic lane. The height of the microphone was $1.5 \mathrm{~m}(5 \mathrm{ft})$ from the pavement level. The instrumentation and calibration of equipment were performed in accordance with the manufacturer's recommended procedure ${ }^{[12]}$.

Noise measurements included the equivalent sound level $\left(\mathrm{L}_{\mathrm{eq}}\right)$, the 10-percentile level, $\mathrm{L}_{10}$, the $\mathrm{L}_{90}, \mathrm{~L}_{50}$, $\mathrm{L}_{\max }$ and the $\mathrm{L}_{\min }$. The Noise Pollution Level $\left(\mathrm{L}_{\mathrm{NP}}\right)$, were also computed for each roadway class and monitoring period. The measurements of noise levels were also made at close proximity to residences in order to determine the exposure to noise pollution levels of people more accurately. The instrument was set to record noise samples at $1 \mathrm{sec}$ intervals during the 20 min monitoring period.

\section{RESULTS AND DISCUSSION}

The mean, the standard deviation, the minimum and the maximum values of traffic volume and speed as 
well as those of the equivalent noise level, $\mathrm{L}_{\mathrm{eq}}$, (peakoff periods) and the highest 10 percentile noise pollution level were computed for the study local streets, collector streets arterial roadways and freeways. Table 1, shows the results for the collector streets.

In general, as the roadway class change from local street, to collector, arterial and finally to freeway, all of the monitored variables-traffic volume, traffic speed and noise pollution indicators-show an increasing trend in their magnitude. The traffic-generated noise pollution level at the study local streets was near or approaching the permitted level of $70 \mathrm{~dB}(\mathrm{~A})$, for outdoor locations. The study collector streets also experienced noise.

Statistical significance of noise variations: The analysis of the measured traffic noise levels above pointed to existence of variations in noise with such variables as the time of day, roadway type and the number of traffic lanes.

In order to determine the existence and the statistical significance of these variations and trends, a cross-classification analysis along with the test of Chisquare were performed on the data. The results for the $\mathrm{L}_{\mathrm{eq}}$ are presented in Table 2 .

As observed earlier, traffic noise was generally higher in the morning than it was in the afternoon or in the evening and the existence and significance of this trend was confirmed by the test of Chi-square $\left(\chi^{2}=31.2, \mathrm{DF}=8, \mathrm{p}<0.001\right)$. The data in Table 2 also show that traffic noise was significantly higher at the study freeways and arterial roadway than it was at collectors or local streets $\left(\chi^{2}=37.3, \mathrm{DF}=12, \mathrm{p}<0.002\right)$, as expected.

Similarly, as the number of traffic lanes of roadways increased so did that level of generated noise. The existence of this trend was also supported by the result of the test of Chi-square $\left(\mathrm{x}^{2}=30.5, \mathrm{DF}=12\right.$, (0.003).

Table 1: Mean statistics of traffic flow and noise pollution at the study collector streets

\begin{tabular}{|c|c|c|c|c|}
\hline \multirow[b]{2}{*}{ Variable name } & \multicolumn{4}{|c|}{ Mean statistics } \\
\hline & Mean & SD & Minimum & Maximum \\
\hline $\begin{array}{l}\text { Traffic volume } \\
\text { (VPH/dir) }\end{array}$ & 998.0 & 661.0 & 184.0 & 2500.0 \\
\hline Traffic speed $\left(\mathrm{km} \mathrm{h}^{-1}\right)$ & 42.8 & 11.5 & 25.0 & 73.0 \\
\hline $\begin{array}{l}\text { Equiv. noise level Leq. } \\
\text { (dBA) (Peak-hours) }\end{array}$ & 75.2 & 4.8 & 68.8 & 81.2 \\
\hline $\begin{array}{l}\text { Equiv. noise level, } \\
\text { Leq (dBA) (off-peak) }\end{array}$ & 71.3 & 2.2 & 65.8 & 74.3 \\
\hline $\begin{array}{l}\text { Highest } 10-\% \\
\text { noise level (dBA) }\end{array}$ & 77.8 & 4.5 & 69.0 & 85.6 \\
\hline
\end{tabular}

Study district noise levels: The application of a category analysis was also extended to the determination of a global picture of traffic noise pollution level at the study districts. This was done for noise during both the peak and the off-peak hours of the day. The $\mathrm{L}_{\mathrm{eq}}$ and the $\mathrm{L}_{10}$ measures of traffic noise represent the average of all measurements at freeway, arterial, collector and roadway locations in each district.

The noise indicators in Fig. 1, shows noise levels at a sample of study districts. The Salehiya district (part of the city center), is noisier than both the Abdullah Al- Salem and Khaldiya districts during both the peak and the off-peak hours of the day. With a mean noise $\mathrm{L}_{\mathrm{eq}}$ level that exceeds $78 \mathrm{~dB}(\mathrm{~A})$ and a mean $\mathrm{L}_{10}$ level of $80 \mathrm{~dB}(\mathrm{~A})$.

This district experienced noise levels which exceeded the permitted levels by significant margin. At such noise levels many of the welfare activities of the exposed public conversation, phoning, working and reading), are adversely affected by noise form traffic. Equivalent noise levels of $72 \mathrm{~dB}(\mathrm{~A})$ and higher during the off-peak hours in Salhiya and Khalidya also indicate that the problem of traffic noise is not only limited to the peak house of the day, but continues throughout most of the working hours of the day and evenings in these districts.

Model predictions: Two models were considered for the prediction of noise levels-the regression models, the US FHWA. The results of predictions by the TNM and the regression models for the peak hour noise levels along with the actual measurements of traffic noise at selected roadway sites are presented in Table 3.

Table 2: Cross-classification of the equivalent peak-hour noise pollution by road type and No. of lanes (percent)

\begin{tabular}{|c|c|c|c|c|c|c|}
\hline \multirow{2}{*}{$\begin{array}{l}\text { Variable } \\
\text { name }\end{array}$} & \multicolumn{6}{|c|}{ Equivalent noise pollution level $\mathrm{dB}(\mathrm{A})$} \\
\hline & $\leq 56$ & $65-70$ & $70-75$ & $75-80$ & $>80$ & Total \\
\hline \multicolumn{7}{|l|}{ Time of day } \\
\hline Morning & 0.0 & 0.0 & 0.0 & 66.7 & 33.3 & 100 \\
\hline Afternoon & 67.9 & 3.6 & 7.1 & 10.7 & 10.7 & 100 \\
\hline Evening & 14.3 & 7.1 & 11.9 & 50.0 & 16.7 & 100 \\
\hline & \multicolumn{6}{|c|}{$\left(\chi^{2}=31.2, \mathrm{DF}=8, \mathrm{p}<0.001\right)$} \\
\hline \multicolumn{7}{|l|}{ Roadway type } \\
\hline Local street & 66.7 & 20.0 & 13.3 & 0.0 & 0.0 & 100 \\
\hline Collectors & 47.4 & 5.2 & 21.1 & 10.5 & 15.8 & 100 \\
\hline Arterial & 42.4 & 0.0 & 3.0 & 45.5 & 9.1 & 100 \\
\hline Freeways & 32.0 & 0.0 & 0.0 & 44.0 & 24.0 & 100 \\
\hline \multicolumn{7}{|c|}{$\left(\mathrm{c}^{2}=37.3, \mathrm{DF}=12, \mathrm{p}<0.002\right)$} \\
\hline \multicolumn{7}{|c|}{ No. of traffic lanes/dir } \\
\hline 1 & 72.7 & 18.2 & 9.1 & 0.0 & 0.0 & 100 \\
\hline 2 & 47.0 & 11.8 & 23.5 & 11.8 & 5.9 & 100 \\
\hline 3 & 40.0 & 0.0 & 3.6 & 40.0 & 16.4 & 100 \\
\hline 4 & 33.3 & 0.0 & 0.0 & 44.5 & 22.2 & 100 \\
\hline \multicolumn{7}{|c|}{$\left(\chi^{2}=30.5, \mathrm{DF}=12, \mathrm{p}<0.003\right)$} \\
\hline
\end{tabular}




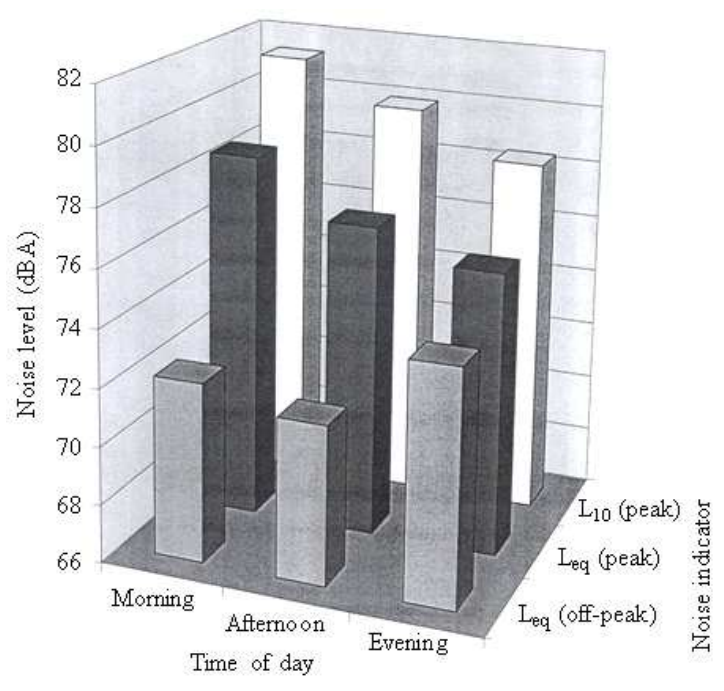

Fig. 1: Noise pollution indicators by district location Salhiya, Abdullah Al-Salem Area and Khaldiya

Table 3: Comparison of measured and model-predicted peak and offpeak noise levels

\begin{tabular}{|c|c|c|c|c|c|}
\hline $\begin{array}{l}\text { District/ } \\
\text { roadway }\end{array}$ & $\begin{array}{l}\text { Measured } \\
\text { noise }\left(L_{e q}\right) \\
d B(A)\end{array}$ & $\begin{array}{l}\text { TNM } \\
\text { predicted } \\
\left(\mathrm{L}_{\mathrm{eq}}\right) \mathrm{dB}(\mathrm{A}) \\
\end{array}$ & $\begin{array}{l}\text { Difference } \\
\text { measured } \\
\text { Vs TNM } \\
\end{array}$ & $\begin{array}{l}\text { Regression } \\
\text { model } \\
\left(\mathrm{L}_{\mathrm{eq}}\right) \mathrm{dB}(\mathrm{A}) \\
\end{array}$ & $\begin{array}{l}\text { Difference } \\
\text { measured } r \\
\text { Vs regression }\end{array}$ \\
\hline \multicolumn{6}{|l|}{ Rawda } \\
\hline \multicolumn{6}{|c|}{ Rawda St. (collector) } \\
\hline Peak & 72.6 & 70.6 & -2.0 & 74.9 & +2.3 \\
\hline Off-Peak & 68.8 & 62.6 & -6.2 & 66.5 & -2.3 \\
\hline \multicolumn{6}{|c|}{ Damascus St. (arterial) } \\
\hline Peak & 77.6 & 71.2 & -6.0 & 79.2 & +1.6 \\
\hline Off-peak & 70.8 & 62.7 & -8.1 & 68.5 & -2.3 \\
\hline \multicolumn{6}{|l|}{ Khaldiya } \\
\hline \multicolumn{6}{|c|}{ Al-riyad FWY } \\
\hline Peak 1 & 77.6 & 73.7 & -3.9 & 80.6 & +3.0 \\
\hline Peak 2 & 77.9 & 72.3 & -5.6 & 78.8 & +0.9 \\
\hline Off-peak & 75.1 & 73.1 & -2.0 & 70.8 & -4.3 \\
\hline \multirow{2}{*}{\multicolumn{6}{|c|}{$\begin{array}{l}\text { Mushrif } \\
6^{\text {th }} \text { RR (FWY) }\end{array}$}} \\
\hline & & & & & \\
\hline Peak 1 & 76.2 & 76.2 & 0.0 & 81.6 & +5.4 \\
\hline Peak 2 & 76.5 & 75.1 & -1.4 & 78.8 & +2.3 \\
\hline Off-peak & 75.8 & 70.0 & -5.8 & 71.9 & -3.9 \\
\hline \multicolumn{6}{|c|}{ Fahaheel FWY } \\
\hline Peak 1 & 78.2 & 76.7 & -1.5 & 84.4 & +6.2 \\
\hline Peak 2 & 80.3 & 78.4 & -1.9 & 82.8 & +2.5 \\
\hline Off-peak & 75.8 & 71.4 & -4.4 & 72.2 & -3.6 \\
\hline
\end{tabular}

An examination of the data in Table 3 reveals that:

- The TNM model consistently underestimates the generated noise levels from traffic nearly all roadway site (with one exception: The 6th Ring Road at Mushrif)

- The peak-hour regression model consistently overestimate the traffic noise levels at all roadway sites

- The levels of underestimation and overestimations of traffic noise is due to the use of REMNEL values which are developed in the USA for vehicle and roadway pavement conditions found in he
USA. REMNEL values need to be developed for the conditions prevailing in the State of Kuwait

\section{CONCLUSION}

- There is an urgent need for a comprehensive urban land-use planning and management. The present unplanned growth of residential and commercial infrastructures will adversely affect the level of traffic congestion and noise pollution in metropolitan Kuwait

- There is urgent for improving the urban public's education concerning daily travel and its impact on both the economy and the environment of the state, as well as on the welfare and health of the urban residents

- The annual vehicle inspection program should also include, in its inspection package, the inspection of vehicles for excessive noise

- Maximum policy-makers' attentions should be given to promote the use of public transit and nonmotorized modes of urban travel in Kuwait. The development of an electric, rubber-tired advance technology surface light-rail system is a must for metropolitan Kuwait

- The default values of the Reference Energy Mean Noise Emission Levels (REMNEL) employed in the FHWA-TNM model are based on the related conditions of roadway, pavement, vehicle and driving behavior found in the USA. A research project should be undertaken to develop REMNEL for Kuwait. Research should continue on monitoring traffic noise pollution trends, as auto ownership increases and urban land-uses change

\section{REFERENCES}

1. Kuwait Municipality, 1995. Department of Environmental Affairs. Kuwait, Report \#417.1995.

2. Sathis, T.C., 1981. Community noise levels in Patras, Greece. J. Acoust. Soc. Am., 69: 468-477. http://www.ncbi.nlm.nih.gov/pubmed/7462470

3. Mehra, C., 1986. Very high noise levels in Indian cities. Arab News, Sunday, November 91986.

4. Person-Kirk, D. and S. Sabir, 1989. The Assessment and prediction of road traffic noise in developing countries. Proceeding of the 11th International Road Federation World Meeting, Korea.

5. Koushki, P., L. Cohn and A. Felimban, 1990. Traffic-generated noise pollution in Riyadh: Its magnitude and perceived health hazards. Research Report No. AT 9-31, KACST, 1990, Saudi Arabia. 
6. Koushki, P.A., 1989. Environmental impact analysis of transportation is a rapidly developing urban areas. Transport Research Board (TRB), TRR No. 1240. http://pubsindex.trb.org/document/view/default.asp ?record $=309037$

7. Koushki, P.A., O. Al-Saleh and S.Y. Ali, 1999. Traffic noise in Kuwait: Profiles and modeling residents' perceptions. J. Urban Plann. Dev., 125: 101-109.

http://scitation.aip.org/getabs/servlet/GetabsServlet ?prog=normal\&id=JUPDDM00012500000300010 $1000001 \&$ idtype $=$ cvips \& gifs $=$ yes

8. Koushki, P., B. Chandrasekhar, A. Ali and M. Al-Sarawi, 2002. Exposure to noise inside transit buses in Kuwait: Measurement and passenger attitudes. J. Transport Rev., 22: 295-308. DOI: $10.1080 / 01441640110103914$
9. Koushki, P., L. Cohn and A. Felimban, 1993. Urban traffic noise in Riyadh, Saudi Arabia: Perceptions and attitudes. J. Transportat. Eng., 119: 751-762. DOI: 10.1061/(ASCE)0733947X(1993)119:5(751).

10. US Department of Transportation Federal Highway Administration (US FHWA), 2004. TNM 2.5 (April 2004): FHWA traffic noise model users guide manual.

11. CRTN., 1988. Calculations of Road Traffic Noise. Department of Transport, London, UK., ISBN: 9780115508479.

12. Brüel and Kjær, 1998. Predictor Type 7810, Version 2.0. User's Manual for the Predictor Platform, Naerum, Denmark. 